\title{
Fermented whey dairy beverage offers protection against Salmonella enterica ssp. enterica serovar Typhimurium infection in mice
}

\author{
M. A. Cordeiro, ${ }^{1}$ E. L. S. Souza, ${ }^{1}$ R. M. E. Arantes, ${ }^{2}$ C. F. Balthazar, ${ }^{3}$ J. T. Guimarães, ${ }^{3}$ H. Scudino, ${ }^{3}$ \\ H. L. A. Silva, ${ }^{3}$ R. S. Rocha, ${ }^{3,4}$ M. Q. Freitas, ${ }^{3}$ E. A. Esmerino, ${ }^{3}$ M. C. Silva, ${ }^{4}$ T. C. Pimentel, ${ }^{5}$ D. Granato, ${ }^{6}$ \\ R. G. B. Costa, ${ }^{7}$ A. G. Cruz, ${ }^{4 *}$ and F. S. Martins ${ }^{1 *}$ \\ ${ }_{1}^{1}$ Department of Microbiology, Institute of Biological Sciences, Federal University of Minas Gerais, 31270-901, Belo Horizonte, MG, Brazil \\ ${ }^{2}$ Department of General Pathology, Institute of Biological Sciences, Federal University of Minas Gerais, 31270-901, Belo Horizonte, MG, Brazil \\ ${ }^{3}$ Universidade Federal Fluminense (UFF), Faculdade de Veterinária, 24230-340, Niterói, RJ, Brazil \\ ${ }^{4}$ Instituto Federal de Educação, Ciência e Tecnologia do Rio de Janeiro, Departamento de Alimentos, Rio de Janeiro, 20270-021, RJ, Brazil \\ ${ }^{5}$ Instituto Federal do Paraná, 87703-536, Paranavaí, PR, Brazil \\ ${ }^{6}$ Universidade Estadual de Ponta Grossa (UEPG), Departmento de Engenharia de Alimentos, 84030-900 Ponta Grossa, Brazil \\ ${ }^{7}$ Empresa de Pesquisa Agropecuária de Minas Gerais (EPAMIG), Instituto de Laticínios Cândido Tostes (ILCT), 36045-560 Juiz de Fora, MG, \\ Brazil
}

\section{ABSTRACT}

Fermented whey dairy beverages are dairy products obtained by fermentation from a mixture of milk and whey. These beverages have important health benefits, which could be improved with the addition of probiotic cultures. This study assessed the protective effect of the cosupplementation of a probiotic culture (Lactobacillus casei 01 ) with a fermented whey dairy beverage against infection by Salmonella enterica ssp. enterica serovar Typhimurium in a murine model. Two fermented whey dairy beverages were prepared: conventional (FWB; starter culture) and probiotic (PFWB; starter and probiotic cultures). In the first set of experiments, Balb/C female mice were treated with FWB or PFWB, challenged with Salmonella Typhimurium, and analyzed for clinical signs, weight loss, and mortality for $20 \mathrm{~d}$ postinfection. In the second set of experiments, mice were treated with FWB or PFWB, challenged with Salmonella Typhimurium, and killed on d 10 postinfection. The liver, colon, and ileum were used for myeloperoxidase, eosinophil peroxidase, and histological analysis and translocation to the liver. The contents from the small intestine were used for secretory IgA determination. The FWB treatment showed a better effect on animal survival (70\%), translocation of the pathogen to the liver (2 out of 10), histopathology (fewer lesions), and inflammation than PFWB, which presented 50\% animal survival, translocation in 5 out of 10 animals,

\footnotetext{
Received January 19, 2019.

Accepted April 10, 2019.

*Corresponding authors: flaviano@icb.ufmg.br and adriano.cruz@
} ifrj.edu.br and higher lesions. The control group presented $40 \%$ animal survival, translocation in 6 out of 10 animals, and severe lesions. Therefore, FWB was deemed to have a greater protective effect against Salmonella Typhimurium infection in the murine model compared with PFWB.

Key words: probiotic, lactic acid bacteria, whey beverage, Salmonella Typhimurium infection

\section{INTRODUCTION}

Each year, 1.9 billion people worldwide fall ill from diarrhea, and 715,000 people die as a result of it. Salmonella is responsible for 180 million cases or $9 \%$ of diarrheal illnesses yearly (Besser, 2018). Salmonellosis is one of the most common bacterial infections in the world and is responsible for a variety of clinical syndromes, including enteric fever, which is usually caused by typhoid or paratyphoid species, enterocolitis, bacteremia, and severe local infections (De Leblanc et al., 2010). Salmonella enterica ssp. enteric serovar Typhimurium has the ability to translocate from the intestine to the liver via the hepatic portal system, causing severe lesions in this organ. Thus, translocation is a parameter for evaluating intestinal invasion by the bacteria and the ability to cross the mucosal barrier to extraintestinal sites such as mesenteric lymph nodes, liver, spleen, kidney, and blood (Berg and Garlington, 1979).

Whey dairy beverages are fermented or nonfermented products that present whey as an ingredient. For fermented whey dairy beverages, the mixture of milk, whey, and other ingredients (e.g., flavorings, sugar) is fermented by conventional starter cultures (Janiaski et al., 2016). The utilization of whey in a food formula- 
tion is important from an environmental and health point of view because whey is a by-product generated in the processing of cheeses and caseins (Janiaski et al., 2016) and is rich in nutrients such as lactose, soluble proteins, lipids, minerals, vitamins, and organic acids (Sabokbar and Khodaiyan, 2016). If discarded without treatment, this industrial effluent may alter the physical and chemical composition of the soil, resulting in decreased crop yield and oxygen availability in water (De Jesus et al., 2015). Considering the health aspects, whey presents a high-quality source of AA, antimicrobial action, growth enhancement of beneficial gut microflora, immune-enhancing properties, control of specific diseases (including cancer), and antitoxin activity (Macwan et al., 2016). The inclusion of probiotic cultures in whey dairy beverages can improve the health effects (Turkmen et al., 2019).

Probiotics are live microorganisms that confer a health benefit on the host when administered in adequate amounts (Hill et al., 2014). The possible benefits of probiotics in the treatment of diarrheal diseases are associated with the $\mathrm{pH}$ reduction in the gut, direct antagonism through the production of antimicrobial compounds, competition for adhesion sites and nutrients, and modulation of the immune system (Wan et al., 2018). Saccharomyces boulardii, Saccharomyces cerevisiae, Escherichia coli EMO, Bifidobacterium longum, Bifidobacterium bifidum, Enterococcus faecium, and Lactobacillus acidophilus conferred a protective effect on the animals challenged with Salmonella Typhimurium, and this beneficial effect was related to a stimulation of the host immune response to treatment with the probiotic culture (Gill et al., 2001; Lima Filho et al., 2004; Silva et al., 2004). However, the health effects associated with probiotic cultures are strainspecific (Mohanty et al., 2019).

The Lactobacillus casei group is the most predominant species of the Lactobacillus genus (Nehzad et al., 2015 ) and comprises 3 phenotypically and genotypically related species: L. casei, L. paracasei, and L. rhamnosus (Hill et al., 2018). Lactobacillus casei 01 has been associated with many health effects, such as protection of the intestinal epithelial cells (Chen et al., 2016) and improvement in the lipid indexes and blood pressure (Sperry et al., 2018). Whey dairy beverages are popular dairy foods worldwide and are considered an excellent food matrix for probiotics (Turkmen et al., 2019), but their efficacy in controlling or relieving diarrheal illnesses has not been reported yet. This study aimed to investigate the protective effect of probiotic whey dairy beverage supplemented with $L$. casei 01 and lactic acid bacteria against the infection by Salmonella Typhimurium in a murine model.

\section{MATERIALS AND METHODS}

\section{Whey Beverage Processing}

Conventional and probiotic whey dairy beverages were processed according to Castro et al. (2013), with some modifications. Pasteurized cow's milk (3.4\% wt/ wt fat; Barra Mansa, São Paulo, Brazil; $70 \%$ vol/ vol) and cheese whey (Ateliê do Queijo, Rio de Janeiro, Brazil; 30\% vol/vol) constituted the dairy basis. They were mixed, heat-treated at 72 to $75^{\circ} \mathrm{C}$ for 15 $\mathrm{s}$, and cooled to 35 to $37^{\circ} \mathrm{C}$ for the addition of lactic acid bacteria (starter: L. lactis R-704, $9 \log \mathrm{cfu} / \mathrm{mL}$ ) in the case of conventional whey dairy beverage (FWB) and lactic acid bacteria and probiotic bacteria (starter: L. lactis R-704 and L. casei 01, 9 and 7-8 $\log$ cfu/ $\mathrm{mL}$, respectively) for probiotic whey dairy beverage (PWFB). Following that, the samples were submitted to the fermentation process at 35 to $37^{\circ} \mathrm{C}$ until reaching $\mathrm{pH} 4.7$ to 4.6 , cooled immediately to $8^{\circ} \mathrm{C}$, packaged in polyethylene bottles $(200 \mathrm{~mL})$, and finally stored at $4 \pm 1^{\circ} \mathrm{C}$ during the study. The products presented $L$. casei counts above 9 to $10 \log \mathrm{cfu} / \mathrm{mL}$, which is the recommended level for processed food to be considered a therapeutic probiotic product (Hill et al., 2014), whereas for L. lactis counts, values above 10 to $11 \mathrm{log}$ $\mathrm{cfu} / \mathrm{mL}$ were observed.

\section{Animal Management and Ethics}

All experimental procedures were carried out according to the standards established by the Brazilian National Council for Control of Animal Experimentation. This study was approved by the Ethics Committee on the Use of Animals of Federal University of Minas Gerais, protocol number 380/2013.

\section{Experimental Animals}

Conventional female BALB/c mice (3 wk old) were purchased from the Center for Animal Care of Federal University of Minas Gerais. All animals were kept in ALE.MIL.01.03 mini-isolators (Alesco, Monte Mor, São Paulo, Brazil). During the experiment, mice received commercial solid feed (Nuvilab Nuvital, Curitiba, Brazil) and filtered water ad libitum and were kept on a ventilated shelf with humidity control (60-80\%), a temperature of 22 to $24^{\circ} \mathrm{C}$, and a 12-h light-dark cycle.

\section{Treatment and Challenge}

For the treatment with FWB or PFWB, mice received a daily dose of $0.1 \mathrm{~mL}$ through an oral gavage during $10 \mathrm{~d}$ before infection, and the treatment contin- 
ued throughout the rest of the experiment $(20 \mathrm{~d})$. For Salmonella Typhimurium experimental infection, bacteria were grown in brain heart infusion broth (Difco, Detroit, MI) overnight at $37^{\circ} \mathrm{C}$. Mice were inoculated intragastrically with $0.1 \mathrm{~mL}$ of a bacterial suspension containing $6 \log \mathrm{cfu} / \mathrm{mL}$.

\section{Experimental Design 1}

For the mortality assay, mice were divided into 3 groups $(\mathrm{n}=10$ each group): control animals receiving sterile water and infected with Salmonella Typhimurium (ST), animals receiving FWB and infected with Salmonella Typhimurium (FWB+ST), and experimental animals receiving PFWB and infected with Salmonella Typhimurium (PFWB+ST). For 20 d postinfection, mice were analyzed for clinical signs, weight loss, and mortality induced by the Salmonella Typhimurium (Figure 1A).

\section{Experimental Design 2}

For inflammatory and histological analysis, mice were divided into 6 groups $(\mathrm{n}=5$ each group): control mice receiving sterile water with no treatment or infection, control mice receiving only FWB, control mice receiving only $\mathrm{PFWB}$, $\mathrm{ST}$ mice, $\mathrm{FWB}+\mathrm{ST}$ mice, and $\mathrm{PFWB}+\mathrm{ST}$ mice. On d 10 postinfection, all mice were killed. The liver was aseptically collected for bacterial translocation. The liver, colon, and ileum were used for myeloperoxidase (MPO), eosinophil peroxidase (EPO), and histological analysis. The small intestine fluid was used for secretory $\operatorname{IgA}(\mathbf{s I g A})$ determination (Figure 1B).

\section{Measurement of Bacterial Translocation}

The liver was aseptically collected and homogenized in sterile PBS (1:10, wt/vol). Serial decimal dilutions were made, plated onto MacConkey agar (Difco), and incubated at $37^{\circ} \mathrm{C}$ for $24 \mathrm{~h}$.

\section{EPO and MPO Activity}

The extent of tissue eosinophil infiltration was assessed by measurement of EPO activity, as previously described by Strath et al. (1985). A total of $100 \mathrm{mg}$ of tissue was homogenized with $1.9 \mathrm{~mL}$ of PBS and

\section{A}

\section{FWB and PFWB treatment}

\begin{tabular}{|l|l|}
\hline 0 & \\
\hline Groups: & \\
- ST & \\
- FWB+ST & Weight loss mortality analysis \\
- PFWB+ST & ST \\
$(\mathrm{n}=10)$ & infection \\
\hline
\end{tabular}

\section{B}

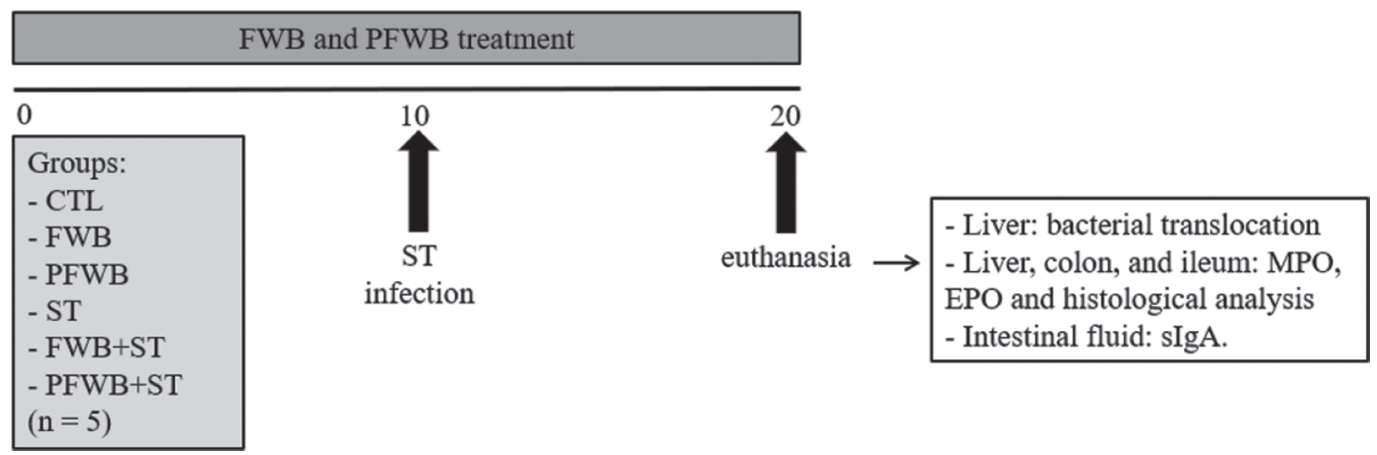

Figure 1. Experimental protocol for conventional fermented whey dairy beverage (FWB) and probiotic fermented whey dairy beverage (PFWB) challenged with Salmonella Typhimurium (ST; single intragastric inoculum of $10^{5}$ cfu). (A) Mortality assay; (B) analysis. CTL = control; ST = group only challenged with Salmonella Typhimurium; FWB+ST = group treated with fermented whey dairy beverage and challenged with Salmonella Typhimurium; PFWB+ST = group treated with probiotic fermented whey dairy beverage and challenged with Salmonella Typhimurium. $\mathrm{MPO}=$ myeloperoxidase; $\mathrm{EPO}=$ eosinophil peroxidase; $\operatorname{sg} \mathrm{A}=$ secretory $\operatorname{Ig} \mathrm{A}$. 
centrifuged at $12,000 \times g$ for $10 \mathrm{~min}$, and then the supernatant was discarded and the erythrocytes were lysed. The supernatant was used in the enzymatic assay by the addition of an equal amount of substrate $(1.5 \mathrm{mmol} / \mathrm{L}$ o-phenylenediamine and $6.6 \mathrm{mmol} / \mathrm{L}$ $\mathrm{H}_{2} \mathrm{O}_{2}$ in $0.075 \mathrm{mmol} / \mathrm{L}$ Tris- $\mathrm{HCl} \mathrm{pH} 8$ ). The reaction was stopped with $50 \mu \mathrm{L}$ of $1 \mathrm{~mol} / \mathrm{L} \mathrm{H}_{2} \mathrm{SO}_{4}$, and the absorbance was read at $492 \mathrm{~nm}$. The extent of neutrophil accumulation in tissue was measured by assaying MPO activity. A portion of tissue was removed, and snaps were frozen in liquid nitrogen. On thawing and processing, the tissue was assayed for MPO activity by measuring the change in optical density at $450 \mathrm{~nm}$ using tetramethylbenzidine.

\section{slgA Determination}

The small intestine fluid was removed, weighed, and diluted with PBS ( $\mathrm{pH} 7.2$ ) containing antiproteases in a ratio of $500 \mathrm{mg}$ of content per $2.0 \mathrm{~mL}$ of PBS. Then, the material was centrifuged $\left(2,000 \times g, 30 \mathrm{~min}, 4^{\circ} \mathrm{C}\right)$, and the supernatant was collected and frozen at $-80^{\circ} \mathrm{C}$ for later determination of Ig. Total sIgA level was determined by ELISA assay, as described by Martins et al. (2009).

\section{Histological Analysis}

Tissue samples from the liver, colon, and ileum were fixed in buffered $4 \%$ formaldehyde and processed for paraffin embedding. The histopathological sections were stained with hematoxylin-eosin for analysis.

\section{Statistical Analysis}

The results were expressed as the average of at least 2 independent experiments. Results are shown as the mean \pm standard error of the mean. Differences were evaluated by the unpaired Student's $t$-test $(\mathrm{n}=2$ samples), 1-way ANOVA, or survival log-rank test. The figures show the test performed for each experiment, and the results with $P \leq 0.05$ were considered significant. Statistical analysis was performed using Sigma Stat version 1.0 (Jandel Scientific Software, San Rafael, CA) for the survival analysis and GraphPad Prism version 5.00 for Windows (GraphPad Software, San Diego, CA) for the other tests.

\section{RESULTS}

\section{Animal Mortality Rate}

The survival rates of the animals treated with conventional fermented whey dairy beverage and probiotic fermented whey dairy beverage infected with Salmonella Typhimurium (FWB+ST and PFWB + ST groups, respectively) are shown in Figure 2. The FWB+ST group showed an increased survival rate (70\%) compared with the ST control group $(40 \% ; P \leq 0.05)$. The PFWB+ST group presented a lower survival rate $(50 \%)$ than the FWB+ST group but a slightly higher rate than the ST control group $(40 \% ; P \leq 0.05)$.

\section{Protective Effect Against Translocation}

Salmonella Typhimurium counts in the liver of animals treated with FWB or PFWB were investigated from d 10 after infection. The results of translocation in the mentioned organ $(\mathrm{n}=10$ each group) indicated a translocation of the pathogen to the liver in 2 out of 10 animals for the FWB+ST group compared with the ST control group, which exhibited translocation in 6 out of 10 animals. In the PFWB+ST group, the translocation was detected in 5 out of 10 animals (data not shown). Therefore, a significant protective effect against translocation in the liver of the animals was observed only with the conventional whey dairy beverage (FWB).

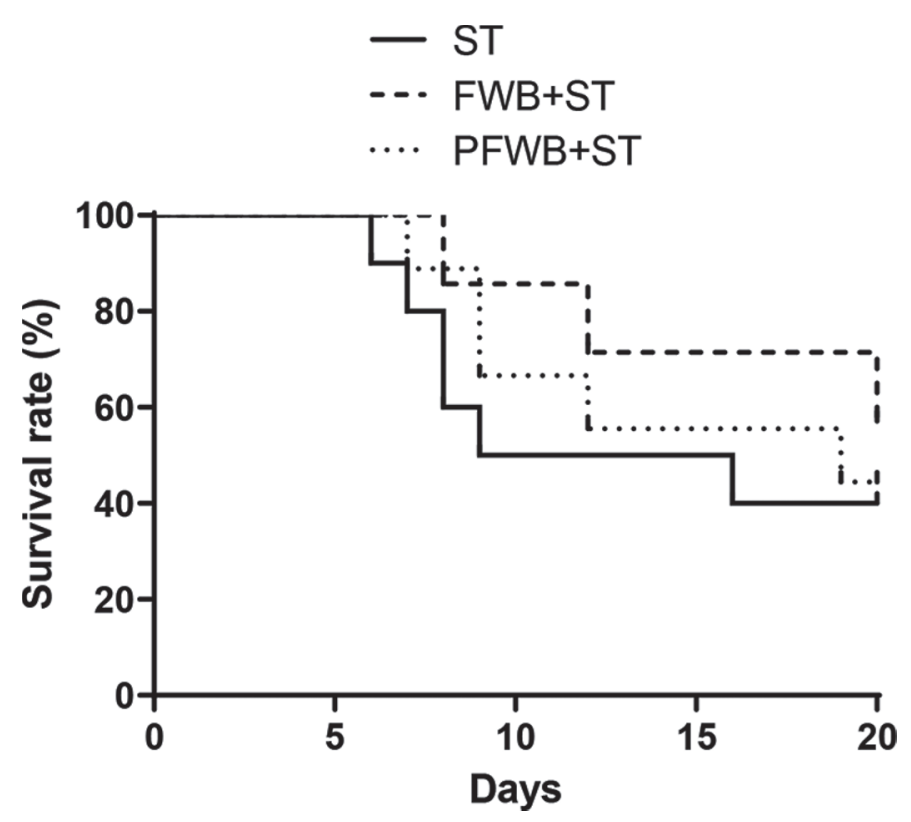

Figure 2. Survival rate (\%) of animals treated during $10 \mathrm{~d}$ with conventional fermented whey dairy beverage (FWB) and probiotic fermented whey dairy beverage (PFWB) challenged with Salmonella Typhimurium (single intragastric inoculum of $10^{5} \mathrm{cfu}$ ). ST $=$ group only challenged with Salmonella Typhimurium; FWB $+\mathrm{ST}=$ group treated with fermented whey dairy beverage and challenged with Salmonella Typhimurium; PFWB+ST = group treated with probiotic fermented whey dairy beverage and challenged with Salmonella Typhimurium ( $\mathrm{n}=10$ for each group). 


\section{Histological Examinations}

Histologic sections of the liver and ileum of mice treated with FWB and PFWB and infected with Salmonella Typhimurium are shown in Figure 3. In the group infected with Salmonella Typhimurium (ST), the histological analysis showed that only 2 of 5 animals presented characteristic lesions of liver infection to an intense degree, whereas the others $(n=3)$ presented an aspect close to normal. No significant changes were observed in the animals of the groups treated with conventional whey dairy beverage $(\mathrm{FWB}+\mathrm{ST})$ and probiotic whey dairy beverage $(\mathrm{PFWB}+\mathrm{ST})$.

Concerning the groups infected with Salmonella Typhimurium, livers with severe lesions were characterized by extensive inflammatory infiltrates, with polymorphonuclear foci associated with necrosis and hepatocyte degeneration (Figure 3C), which are distributed diffusely in the organ. Animals infected with Salmonella Typhimurium and treated with FWB presented an improved physical appearance (Figure 3F). Areas with coagulation necrosis in the territories of terminal circulation were observed and are probably associated with the thromboembolic phenomena in the groups treated with PFWB (Figure 3G). Intermediate lesions presented focal infiltrate, with preserved areas between the foci of lesion and tissue destruction, as well as small foci of coagulative necrosis. Some areas of intact hepatocytes were observed but with eosinophilia and cytoplasmic retraction (degenerative changes; not shown). Normal or nonsignificant livers infected with Salmonella Typhimurium treated with FWB (not shown) or with PFWB (not shown) showed preserved lobular architecture and cellularity within normality patterns.

The lesions produced in the intestinal mucosa (ileum) of animals infected by Salmonella Typhimurium were microscopic and focal and affected only the submucosa with edema. Furthermore, they have some points with a slight increase in intraepithelial cellularity and slight distortion of the villi architecture that were fused (Figure 3D). In the group of animals infected by Salmonella Typhimurium (ST), the lesion in the ileum concerned only the submucosal edema. In the group infected by Salmonella Typhimurium and treated with FWB (FWB+ST), 1 of 9 animals had a minimal lesion in the ileum (Figure 3F), whereas the group infected by Salmonella Typhimurium and treated with PFWB $(\mathrm{PFWB}+\mathrm{ST})$ presented a discrete and focal lesion in the ileum mucosa (Figure $3 \mathrm{H}$ ).

\section{MPO and EPO Levels}

The activity of EPO and MPO was measured to investigate whether treatment with conventional fer- mented whey dairy beverage $(\mathrm{FWB}+\mathrm{ST})$ and probiotic fermented whey dairy beverage $(\mathrm{PFWB}+\mathrm{ST})$ would reduce the infiltration of eosinophils and neutrophils in both the intestinal mucus layer (ileum and colon) and liver of the animals. Although Salmonella Typhimurium increased MPO activity in the ileum, colon, and liver of mice, both treatments were not able to reduce the enzyme activity in the liver and colon $(P>0.05$; Figure $4 \mathrm{~A}$ and $\mathrm{C}$ ), whereas a significant reduction (Figure 4B) was observed in the ileum. The EPO activity in the treated animals demonstrated that the probiotic $L$. casei 01 was not able to reduce the production of eosinophils in the organs, as shown in Figure 4 (D, E, and $\mathrm{F}$ ). A small reduction was observed in the ileum, with no significant differences $(P>0.05)$.

\section{slgA Levels}

A slight increase in the production of sIgA was observed in the intestinal fluid of animals treated with conventional fermented whey dairy beverage $(\mathrm{FWB}+\mathrm{ST})$ and probiotic fermented whey dairy beverage (PFWB+ST) infected with Salmonella Typhimurium after $10 \mathrm{~d}$ of treatment compared with the control challenged only with the starter bacteria (ST; Figure 5). However, the correlation among the $\mathrm{ST}, \mathrm{FWB}+\mathrm{ST}$, and $\mathrm{PFWB}+\mathrm{ST}$ groups was not significant $(P>0.05)$.

\section{DISCUSSION}

In the present study, the oral daily administration of fermented whey dairy beverages improved the survival rates of Salmonella Typhimurium-infected mice, with a survival rate of 70 and $50 \%$ of animals treated with conventional fermented whey beverage (FWB) and probiotic fermented whey beverage (PFWB), respectively. This result shows that FWB presented better survival against the pathogen than PFWB in the parameter evaluated. The results of the present study are in agreement with Castillo et al. (2013), who found mortality rates between 7 and $80 \%$ in animals infected by Salmonella and treated with lactobacilli. A protective effect is considered when it reduces mortality by $50 \%$ compared with the only samples infected with a pathogen. Thus, FWB may have greater protection against the pathogen compared with PFWB. This is the first report on the protective effect of fermented whey dairy beverage against Salmonella Typhimurium infection, thus revealing the potential and innovative treatment option.

Bacterial translocation is the involvement of bacteria in invasive intestinal infection under normal conditions in the body, which can lead to modulation of the host's immune system through the indigenous microbiota (Berg, 1996). Translocation studies revealed that mice 
challenged with Salmonella Typhimurium and treated with fermented whey dairy beverage $(\mathrm{FWB}+\mathrm{ST})$ demonstrated lower bacterial translocation to the liver compared with the control mice (ST). Regarding the animals treated with probiotic fermented whey beverage $(\mathrm{PFWB}+\mathrm{ST})$, a higher translocation was observed
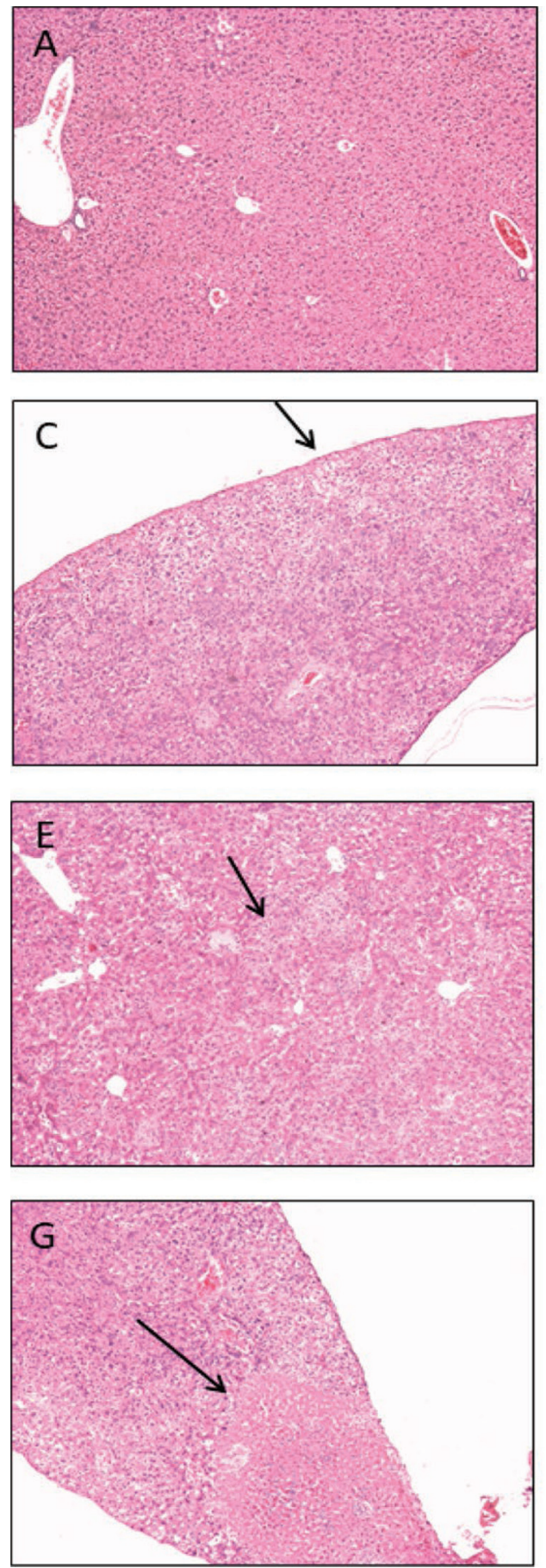

compared with $\mathrm{FWB}+\mathrm{ST}$, but a similar translocation was observed compared with the control (ST), which was expected based on the evaluation of mortality data (Figure 2). Castillo et al. (2013) observed a protective effect of lactobacilli against Salmonella up to $10 \mathrm{~d}$ after the challenge. Therefore, the findings of the present
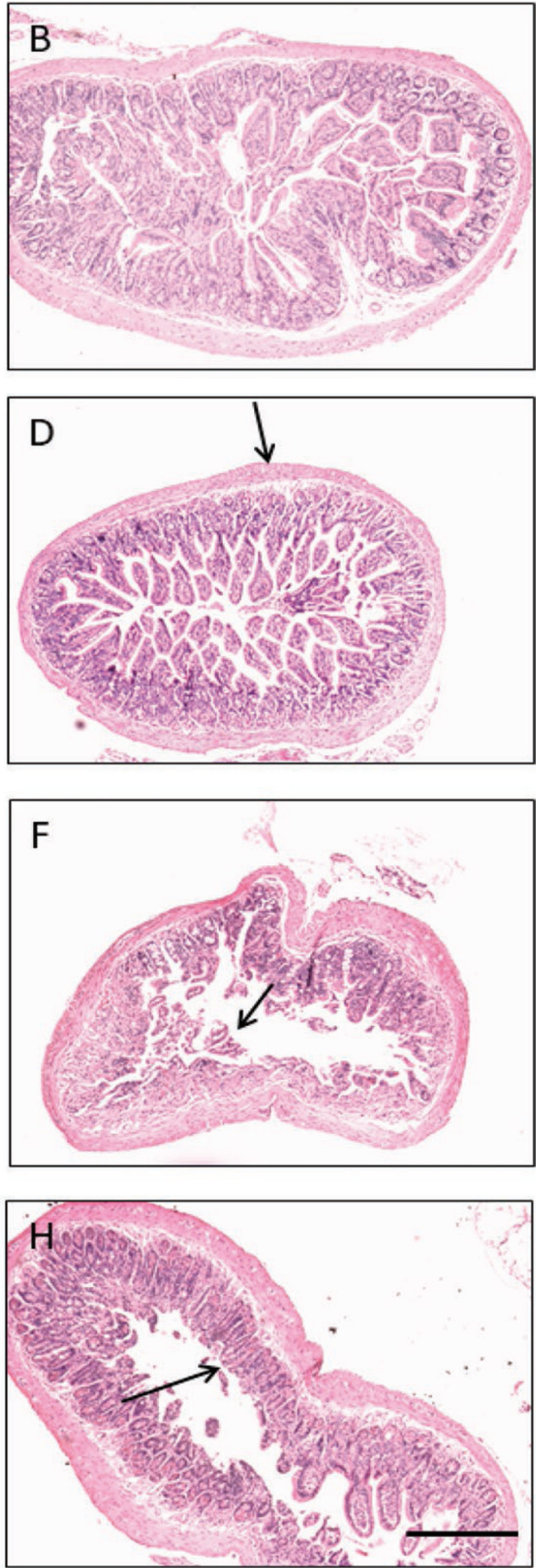

Figure 3. Histological aspects of the liver and ileum of control mice (A, B), mice treated with conventional fermented whey dairy beverage (E, F), and mice treated with probiotic fermented whey dairy beverage (G, H) for $10 \mathrm{~d}$ and then challenged with Salmonella Typhimurium. (C, D) Group challenged only with Salmonella Typhimurium. Hematoxylin and eosin stained; arrows indicate inflammation foci. Bar $=5 \mu \mathrm{m}$. 
A

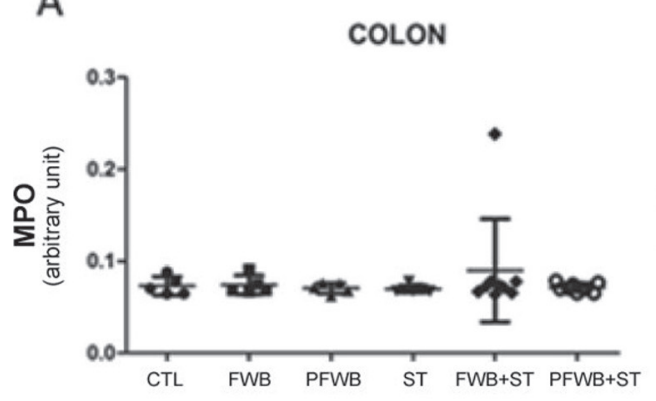

C

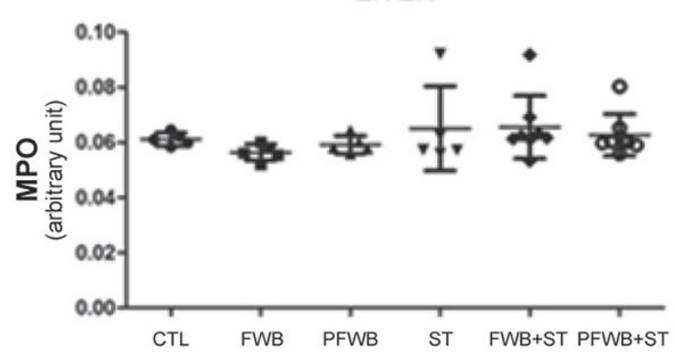

E

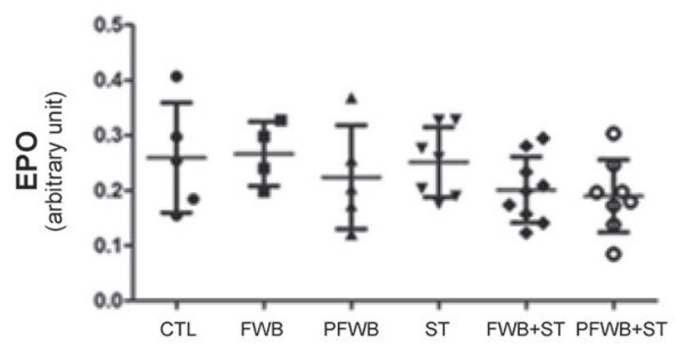

B

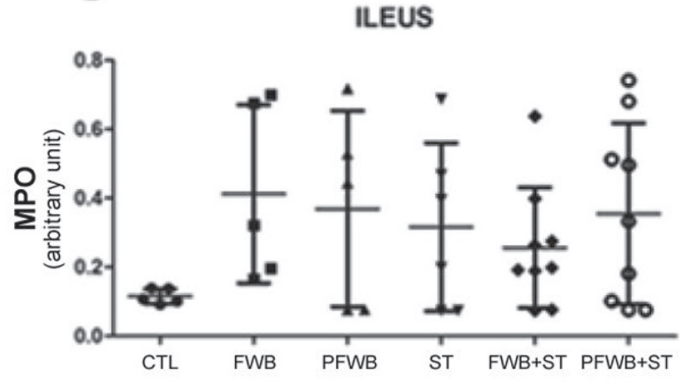

D

COLON

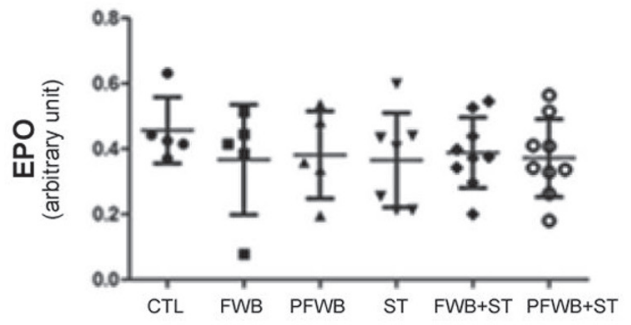

F

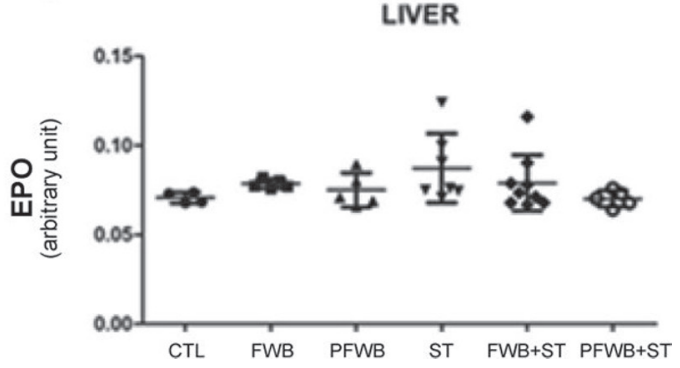

Figure 4. Quantification of myeloperoxidase (MPO; A-C) and eosinophil peroxidase (EPO; D-F) activity in the ileum, colon, and liver of mice treated with conventional fermented whey dairy beverage (FWB) and probiotic fermented whey dairy beverage (PFWB) challenged with Salmonella Typhimurium ( $\mathrm{n}=5$ for each group). CTL = control; $\mathrm{ST}=$ Salmonella Typhimurium; FWB $+\mathrm{ST}=$ fermented whey dairy beverage challenged with Salmonella Typhimurium; PFWB+ST = probiotic fermented whey dairy beverage challenged with Salmonella Typhimurium. Error bars are the SD of the EPO in the ileus and liver, and the midline is the mean value.

study suggest a degree of protection of fermented whey dairy beverage against the translocation to the liver in Salmonella Typhimurium infection.

The translocation and histopathological evaluation reinforced the protective effect of the FWB in vivo, promoted by the microbial survival in the intestinal tract of mice, in which the liver and ileum were more preserved, compared with the control (ST). On the other hand, PFWB showed a greater lesion in the liver, with areas of necrosis and a slight lesion in the ileum, similar to the control. Conversely, our data differ from the results obtained by Chiva et al. (2002), who studied a model of hepatic cirrhosis in rats and reported a protetive effect of Lactobacillus johnsonii, suggesting that the modulation of the microbiota of these animals by the probiotic lactobacilli can reduce the burden of pathogens in the gut.

The MPO and EPO activities were evaluated to assess the efficacy of FWB and PFWB in the reduction of intestinal mucosal infiltrates by neutrophils and eosinophils. The evaluation of the activity of the MPO enzyme was used as an index of recruitment of neutrophils in the tissues (Souza et al., 2000), and the evaluation of the activity of the EPO enzyme was used as an index of recruitment of eosinophils in the tissues (Strath et al., 1985). Although no significant differences were observed in the MPO and EPO activity in the groups treated with FWB and PFWB, the group treated with conventional fermented whey dairy beverage presented a reduction of MPO and EPO activity in the ileum. 
Trindade et al. (2018) found no reduction of MPO in animals treated with different probiotics (Lactobacillus rhamnosus HN001, L. acidophilus NCFWB, Bifidobacterium lactis HN019). In relation to the EPO activity, Trindade et al. (2018) also reported lower activity after the treatment, as observed in the results related to the ileum. In the present study, Salmonella Typhimurium infection may have induced intestinal inflammation in the animals, and treatment with conventional fermented whey dairy beverage (FWB+ST) has been shown to alleviate inflammation in this organ, which was not observed in the treatment with probiotic fermented whey dairy beverage $(\mathrm{PFWB}+\mathrm{ST})$. According to Frece et al. (2014), L. lactis is considered a potential functional starter culture because it exhibits good survival in the simulated gastrointestinal environment in vitro, desirable adhesive properties in intestinal epithelial cells of mice, and sufficient antimicrobial activity against pathogen microorganisms. In addition, some studies have reported the potential of L. lactis in the treatment of murine colitis (Steidler et al., 2000), the ability to attenuate Salmonella adhesion to human intestinal cells in vitro (Zhang et al., 2016), and the production of nisin-like bacteriocin active against gram-positive and gram-negative bacteria (Azhar et al., 2017), which can explain the good result of the fermented whey dairy beverage made with starter cultures against Salmonella Typhimurium.

Immunoglobulin A antibodies activate the immature innate immune system against pathogen infections (Macpherson et al., 2000). In the present study, a small increase in $\operatorname{sIg} \mathrm{A}$ was observed in the intestinal fluid of

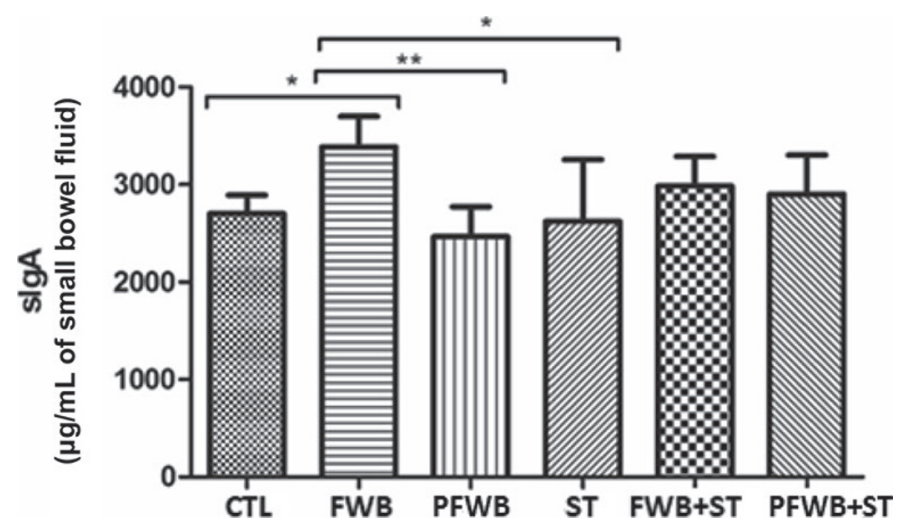

Figure 5. Intestinal levels of secretory $\operatorname{IgA}(\operatorname{sIgA})$ treated with conventional fermented whey dairy beverage (FWB) and probiotic fermented whey dairy beverage (PFWB; $\mathrm{n}=5$ for each group). 1-way ANOVA test $(P<0.05)$. CTL $=$ control; $\mathrm{ST}=$ Salmonella Typhimurium; FWB $+\mathrm{ST}=$ conventional fermented whey dairy beverage challenged with Salmonella Typhimurium; $\mathrm{PFWB}+\mathrm{ST}=$ probiotic fermented whey dairy beverage challenged with Salmonella Typhimurium. ${ }^{*} P<0.05,{ }^{* *} P<0.01$. Error bars indicate the SD of the sIgA in the different groups. animals treated with both beverages. Vinderola et al. (2007) also reported an increase in sIgA in the animals treated with milk fermented by Lactobacillus helveticus. Secretory IgA can prevent the adhesion of pathogens to the intestinal mucosa by adhering to the bacterial surface and attaching it to the mucosal layer of the intestinal epithelium, thereby preventing translocation to internal organs (Hajishengallis et al., 1992).

The present study demonstrated that there is a small protective effect of oral administration of probiotic whey dairy beverage against Salmonella Typhimurium, mainly related to its survival, and increases in sIgA levels. However, even though probiotic strain has reported immunomodulatory properties at the intestinal level, the daily administration of the probiotic fermented whey dairy beverage with $L$. casei 01 in this infection model was considered less effective compared with the conventional whey dairy beverage fermented only by the starter culture. Similar findings were noted by Lollo et al. (2013), who reported that probiotic whey beverage offered decreased immunoprotection compared with probiotic yogurt in Wistar rats submitted to exhausting exercise.

The nonsignificant effect of the probiotic addition (L. casei 01) against Salmonella Typhimurium could be related to the strain specificity or to the presence of the starter culture, which could have more protective potential than the probiotic culture. The strain specificity can be observed in the previous studies (Mohanty et al., 2019). A protective effect of B. bifidum (Bayoumi and Griffiths, 2012) in the inhibition of Salmonella was observed, whereas L. plantarum 299v had no influence (Lönnermark et al., 2015). Therefore, strain specificity should be considered when selecting probiotic cultures (Zhang et al., 2016). Piatek et al. (2019) reported that $B$. longum, L. rhamnosus, L. acidophilus, and L. plantarum had inhibitory effects on the proliferation of Salmonella Typhimurium. However, they stated that the effect was strain-specific and related to the presence of other cultures in the medium, as Streptococcus thermophilus St-21 and L. helveticus SP-27 had the strongest inhibition. Therefore, in the present study, the starter culture (L. lactis) had a stronger effect than the probiotic culture. In addition, the presence of the probiotic culture inhibited the protective effect of the starter culture, but the product had a similar effect as the control. This effect is probably related to competition among the microorganisms (Zhang et al., 2016; Piatek et al., 2019). Lactobacillus casei probably produced organic acids and antimicrobial compounds (Mohanty et al., 2019) that inhibited the activity of the starter cultures but not of the Salmonella Typhimurium. Further studies should evaluate in a deeper way the interactions 
among the starter and probiotic cultures in whey dairy beverages.

Several benefits are attributed to probiotic whey beverages for consumers' health, which was validated using in vivo experiments (Turkmen et al., 2019). Our findings reinforce the need to evaluate the interaction of probiotic strain and food matrix (Flach et al., 2018; Jangra et al., 2019). For example, L. casei 01, when added in probiotic Prato cheese, presented a positive effect in alleviating hypertension symptoms in overweight women (Sperry et al., 2018) and alleviated the formation of renal calculi (Martins et al., 2018).

Finally, it is important to point out that most commercial whey beverages available in the market (fruit flavored, chocolate drinks) are conventional fermented formulations. They are consumed by children, adults, and the elderly on a regular basis, which makes the results of this study interesting and with practical application, as their consumption can provide additional benefits against infections with enteric pathogens, such as Salmonella. In a practical point of view, the results of this study are useful and can help the dairy industry to choose a starter culture suitable to be added in the formulation of dairy drinks.

\section{CONCLUSIONS}

The present study suggests the important and possible therapeutic role of daily intake of conventional and probiotic fermented whey beverages to enhance the protection against Salmonella Typhimurium. The conventional fermented whey dairy beverage presented a better protective effect against Salmonella Typhimurium infection in a murine model and was able to protect the mice against the responses produced by the pathogenic bacteria (inflammatory response and tissue damage) compared with the probiotic fermented whey dairy beverage.

\section{ACKNOWLEDGMENTS}

This work was supported by grants from the Brazilian National Council for Scientific and Technological Development $(\mathrm{CNPq})$, the Ministry of Science and Technology (MICT), and Coordenação de Aperfeiçoamento de Pessoal de Nível Superior (CAPES), Ministry of Education (all of Brazil). The funders had no role in study design, data collection and analysis, decision to publish, or preparation of the manuscript.

\section{REFERENCES}

Azhar, N. S., N. H. N. Zin, and T. H. T. A. Hamid. 2017. Lactococcus lactis strain A5 producing nisin-like bacteriocin active against gram positive and negative bacteria. Trop. Life Sci. Res. 28:107118.

Bayoumi, M. A., and M. W. Griffiths. 2012. In vitro inhibition of expression of virulence genes responsible for colonization and systemic spread of enteric pathogens using Bifidobacterium bifidum secreted molecules. Int. J. Food Microbiol. 156:255-263.

Berg, R. D. 1996. The indigenous gastrointestinal microflora. Trends Microbiol. 4:430-435.

Berg, R. D., and A. W. Garlington. 1979. Translocation of certain indigenous bacteria from the gastrointestinal tract to the mesenteric lymph nodes and other organs in a gnotobiotic mouse model. Infect. Immun. 23:403-411.

Besser, J. M. 2018. Salmonella epidemiology: A whirlwind of change. Food Microbiol. 71:55-59.

Castillo, N. A., A. De Moreno De Leblanc, C. M. Galdeano, and G. Perdigón. 2013. Comparative study of the protective capacity against Salmonella infection between probiotic and nonprobiotic lactobacilli. J. Appl. Microbiol. 114:861-876.

Castro, W. F., A. G. Cruz, D. Rodrigues, G. Ghiselli, C. A. F. Oliveira, J. A. F. Faria, and H. T. Godoy. 2013. Effects of different whey concentrations on physicochemical characteristics and viable counts of starter bacteria in dairy beverage supplemented with probiotics. J. Dairy Sci. 96:96-100.

Chen, Y. P., C. A. Hsu, W. T. Hung, and M. J. Chen. 2016. Effects of Lactobacillus paracasei 01 fermented milk beverage on protection of intestinal epithelial cell in vitro. J. Sci. Food Agric. 96:2154-2160.

Chiva, M., G. Soriano, I. Rochat, C. Peralta, F. Rochat, T. Llovet, B. Mirelis, E. J. Schiffrin, C. Guarner, and J. Balanzó. 2002. Effect of Lactobacillus johnsonii La1 and antioxidants on intestinal flora and bacterial translocation in rats with experimental cirrhosis. J. Hepatol. 37:456-462.

De Jesus, C. S. A., V. G. E. Ruth, S. F. R. Daniel, and A. Sharma. 2015. Biotechnological alternatives for the utilization of dairy industry waste products. Adv. Biosci. Biotechnol. 6:223-235.

De Leblanc, A. D. M., C. M. Galdeano, C. A. Dogi, E. Carmuega, R. Weill, and G. Perdigon. 2010. Adjuvant effect of a probiotic fermented whey beverage in the protection against Salmonella enteritidis serovar Typhimurium infection: Mechanisms involved. Int. J. Immunopathol. Pharmacol. 23:1235-1244.

Flach, J., M. Waal, M. Nieuwboer, E. Claassen, and O. Larsen. 2018. The underexposed role of food matrices in probiotic products: Reviewing the relationship between carrier matrices and product parameters. Crit. Rev. Food Sci. Nutr. 58:2570-2584.

Frece, J., J. Cvrtila, I. Topić, F. Delaš, and K. Markov. 2014. Lactococcus lactis ssp. lactis as potential functional starter culture. Food Technol. Biotechnol. 52:489-494.

Gill, H. S., H. Lin, and K. J. Rutherfurd. 2001. Protection against tranlocating Salmonella Typhimurium infection in mice by feeding the immune-enhancing probiotic Lactobacillus rhamnosus strain HN001. Med. Microbiol. Immunol. (Berl.) 190:97-104.

Hajishengallis, G., E. Nikolova, and M. W. Russell. 1992. Inhibition of Streptococcus mutans adherence to saliva-coated hydroxyapatite by human secretory immunoglobulin A (S-IgA) antibodies to cell surface protein antigen I/II: Reversal by IgA1 protease cleavage. Infect. Immun. 60:5057-5064.

Hill, C., F. Guarner, G. Reid, G. R. Gibson, D. J. Merenstein, B. Pot, L. Morelli, R. B. Canani, H. J. Flint, S. Salminen, P. C. Calder, and M. E. Sanders. 2014. Expert consensus document: The International Scientific Association for Probiotics and Prebiotics consensus statement on the scope and appropriate use of the term probiotic. Nat. Rev. Gastroenterol. Hepatol. 11:506-514.

Hill, D., I. Sugrue, C. Tobin, C. Hill, C. Stanton, and R. P. Ross. 2018. The Lactobacillus casei group: History and health related applications. Front. Microbiol. 9:2107.

Jangra, S., R. K. Sharma, R. Pothuraju, and G. Bhakri. 2019. Milk fermented with Lactobacillus casei NCDC19 improves high fat and sucrose diet alters gene expression in obese mice. Int. Dairy J. 90:15-22.

Janiaski, D. R., T. C. Pimentel, A. G. Cruz, and S. H. Prudencio. 2016. Strawberry-flavored yogurts and whey beverages: What is the sensory profile of the ideal product? J. Dairy Sci. 99:5273-5283. 
Lima Filho, J. V. M., L. Q. Vieira, R. M. E. Arantes, and J. R. Nicoli. 2004. Effect of the Escherichia coli EMO on experimental infection by Salmonella enterica ssp. enterica serovar Typhimurium in gnotobiotic mice. Braz. J. Med. Biol. Res. 37:10051013.

Lollo, P. C. B., C. S. Moura, P. N. Morato, A. G. Cruz, W. F. Freitas, C. B. Betim, L. Nisishima, J. A. F. Faria, M. M. Marostica Jr., C. A. F. Oliveira, and J. Amaya-Farfan. 2013. Probiotic yogurt offers higher immune-protection than probiotic whey beverage. Food Res. Int. 54:118-124.

Lönnermark, E., G. Lappas, V. Friman, A. E. Wold, E. Backhaus, and I. Adlerberth. 2015. Effects of probiotic intake and gender on nontyphoid Salmonella infection. J. Clin. Gastroenterol. 49:116-123.

Macpherson, A. J., D. Gatto, E. Sainsbury, G. R. Harriman, H. Hengartner, and R. M. Zinkernagel. 2000. A primitive T cell-independent mechanism of intestinal mucosal IgA responses to commensal bacteria. Science 288:2222-2226.

Macwan, S. R., B. K. Dabhi, S. C. Parmar, and K. D. Aparnathi. 2016. Whey and its utilization. Int. J. Curr. Microbiol. Appl. Sci. $5: 134-155$.

Martins, A. A., V. A. Santos-Junior, E. R. T. Filho, H. L. A. Silva, M. V. S. Ferreira, J. S. Graça, E. A. Esmerino, P. C. B. Lollo, M. Q. Freitas, A. S. Sant'Ana, L. E. O. Costa, R. S. L. Raices, M. C. Silva, A. G. Cruz, and M. E. Barros. 2018. Probiotic Prato cheese consumption attenuates development of renal calculi in animal model of urolithiasis. J. Funct. Foods 49:378-383.

Martins, F. S., A. A. Silva, A. T. Vieira, F. H. Barbosa, R. M. Arantes, M. M. Teixeira, and J. R. Nicoli. 2009. Comparative study of Bifidobacterium animalis, Escherichia coli, Lactobacillus casei and Saccharomyces boulardii probiotic properties. Arch. Microbiol. 191:623-630.

Mohanty, D., S. Panda, S. Kumar, and P. Ray. 2019. In vitro evaluation of adherence and anti-infective property of probiotic Lactobacillus plantarum DM 69 against Salmonella enterica. Microb. Pathog. 126:212-217.

Nezhad, M. H., M. A. Hussain, and M. L. Britz. 2015. Stress responses in probiotic Lactobacillus casei. Crit. Rev. Food Sci. Nutr. $55: 740-749$

Piatek, J., H. Sommermeyer, M. Bernatek, A. Ciechelska-Rybarczyk, B. Oleskow, L. S. Mikkelsen, and K. B. Barken. 2019. Persistent infection by Salmonella enterica servovar Typhimurium: Are synbiotics a therapeutic option? A case report. Benef. Microbes 10:211-217.

Sabokbar, N., and F. Khodaiyan. 2016. Total phenolic content and antioxidant activities of pomegranate juice and whey based novel beverage fermented by kefir grains. J. Food Sci. Technol. 53:739747 .
Silva, A. M., F. H. F. Barbosa, R. Duarte, L. Q. Vieira, R. M. E. Arantes, and J. R. Nicoli. 2004. Effect of Bifidobacterium longum ingestion on experimental salmonellosis in mice. J. Appl. Microbiol. 97:29-37.

Souza, D. G., D. C. Cara, G. D. Cassali, S. F. Coutinho, M. R. Silveira, S. P. Andrade, S. P. Poole, and M. M. Teixeira. 2000. Effects of the PAF receptor antagonist UK74505 on local and remote reperfusion injuries following ischaemia of the superior mesenteric artery in the rat. Br. J. Pharmacol. 131:1800-1808.

Sperry, M. F., H. L. Silva, C. F. Balthazar, E. A. Esmerino, S. Verruck, E. S. Prudencio, R. P. C. Neto, M. I. B. Tavares, J. C. Peixoto, F. Nazzaro, R. S. Rocha, J. Moraes, A. S. G. Gomes, R. S. L. Raices, M. C. Silva, D. Granato, T. C. Pimentel, M. Q. Freitas, and A. G. Cruz. 2018. Probiotic Minas Frescal cheese added with L. casei 01: Physicochemical and bioactivity characterization and effects on hematological/biochemical parameters of hypertensive overweighted women - A randomized double-blind pilot trial. J. Funct. Foods 45:435-443.

Steidler, L., W. Hans, L. Schotte, S. Neirynck, F. Obermeier, W. Falk, W. Fiers, and E. Remaut. 2000. Treatment of murine colitis by Lactococcus lactis secreting interleukin-10. Science 289:1352-1355.

Strath, M., D. J. Warren, and C. J. Sanderson. 1985. Detection of eosinophils using an eosinophil peroxidase assay. Its use as an assay for eosinophil differentiation factors. J. Immunol. Methods 83:209-215.

Trindade, L. M., V. D. Martins, N. M. Rodrigues, E. L. S. Souza, F. S. Martins, G. M. F. Costa, C. M. Almeida-Leite, A. M. C. Faria, V. N. Cardoso, T. U. Maioli, and S. V. Generoso. 2018. Oral administration of Simbioflora ${ }^{\circledR}$ (synbiotic) attenuates intestinal damage in a mouse model of 5-fluorouracil-induced mucositis. Benef. Microbes 9:477-486.

Turkmen, N., C. Akal, and B. Ozer. 2019. Probiotic dairy-based beverages: A review. J. Funct. Foods 53:62-75.

Vinderola, G., C. Matar, and G. Perdigón. 2007. Milk fermented by Lactobacillus helveticus R389 and its non-bacterial fraction confer enhanced protection against Salmonella enteritidis serovar Typhimurium infection in mice. Immunobiology 212:107-118.

Wan, M. L. Y., S. J. Forsythe, and H. El-Nezami. 2018. Probiotics interaction with foodborne pathogens: A potential alternative to antibiotics and future challenges. Crit. Rev. Food Sci. Nutr. 5:1-14.

Zhang, J. S., A. Guri, M. Corredig, R. Morales-Rayas, A. Hassan, M. Griffiths, and G. LaPointe. 2016. Lactococcus lactis ssp. cremoris strain JFR1 attenuates Salmonella adhesion to human intestinal cells in vitro. Food Res. Int. 90:147-153. 